\title{
The Research of Civil Engineering Certification Information Management System
}

\author{
Hualong Cai ${ }^{1}$, Chen Peng ${ }^{1, *}$, Chengyu Zhu ${ }^{1}$ and Ming Ouyang ${ }^{1}$ \\ 'School of Civil Engineering, Jiaying University, Meizhou, Guangdong, China
}

\begin{abstract}
In recent years, engineering education professional certification is an important direction for the development of engineering education in our country. Colleges and universities across the country have established various professional student training systems in accordance with the requirements of engineering certification. This article gives a brief introduction to the design and development process of civil engineering certification management information system according to the training standards of engineering certification. The aim of this study is to solve the problem of low efficiency of civil engineering professional engineering certification.
\end{abstract}

\section{Background of Research}

In recent years, engineering education professional certification is an important direction for the development of engineering education in China. Since China formally joined the "Washington Agreement" in June 2016, all colleges and universities across the country have adopted engineering certification requirements as a reference standard and combined the characteristics of the school to establish a training system for students in various majors. This will promote the development of engineering education. With the development of information technology, the use of information technology to realize the management of engineering professional certification has become a main method of engineering certification management. ${ }^{[1-2]}$

Therefore, we take the improvement of the information capability of civil engineering certification assessment as the starting point, and in accordance with the training standards of engineering certification, we have designed and developed a civil engineering certification information management system. Firstly, a demand analysis of engineering education management is carried out, and on the basis of demand analysis, a prototype design of the information management system, including frame page design and functional module design, is carried out.

\section{System Functions}

\subsection{Overall system function}

According to the requirements of the 2016 version of the professional certification self-evaluation report guide of the China Engineering Education Certification Association, the self-evaluation materials must provide the training goals, graduation requirements, training programs, periodic evaluation data of the achievement of the course and the corresponding periodic evaluation system. ${ }^{[3]}$ It has been shown in chart 1.

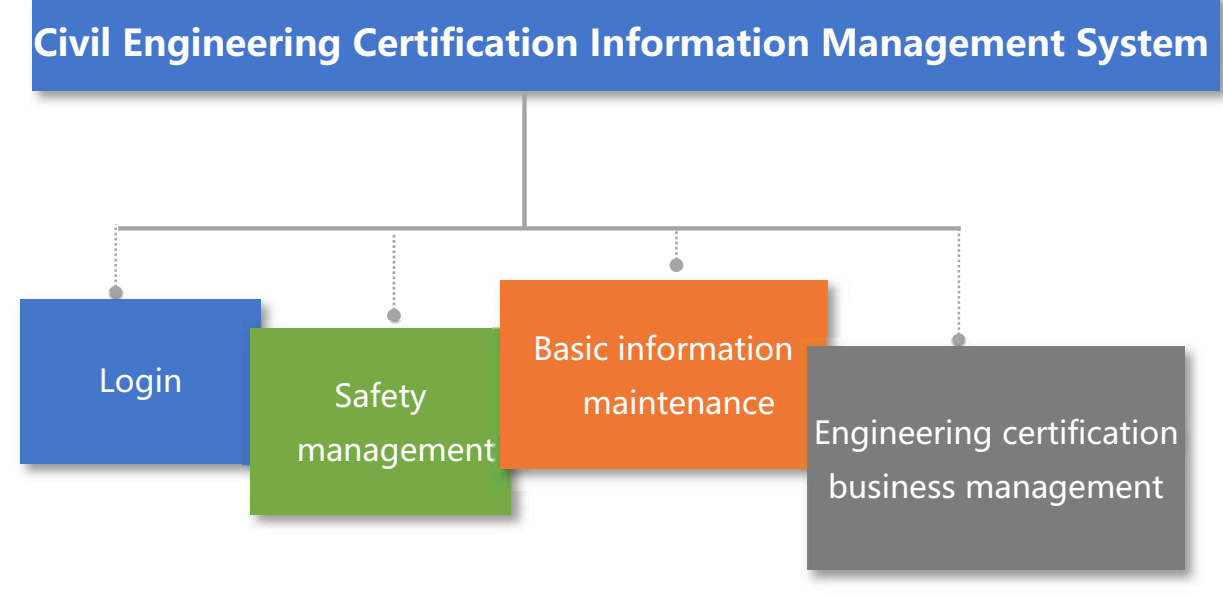

Figure 1. Overall function

\footnotetext{
* Corresponding author's e-mail: whucad@whu.edu.com
} 
In summary, the overall functions of the system can be divided into four modules: login module, security management module, basic information maintenance module and engineering certification business management module. Among them, the main function of the login module is to realize the safe login and safe logout of system users, ensuring that users can log in and log out of the system safely and conveniently. The security management module is based on the role access control mechanism, which mainly realizes the role definition, authority management and maintenance of the login user, ensuring that the user obtains the corresponding operation page after logging in according to different roles. The basic information maintenance module mainly realizes the maintenance of basic system information, including basic user information, basic role information, basic module information, etc. The engineering certification business management module is the core module of the system, which mainly realizes the management and maintenance of related document data under the engineering education certification concept. The design and development of an engineering education information management system based on the above functional modules can meet the requirements of the system and improve the efficiency of information management and maintenance.

\subsection{System core functions}

Based on the basic functional modules, this system combines the characteristics of the college to divide the professional certification evaluation management into the following five parts. It has been shown in chart 2 .

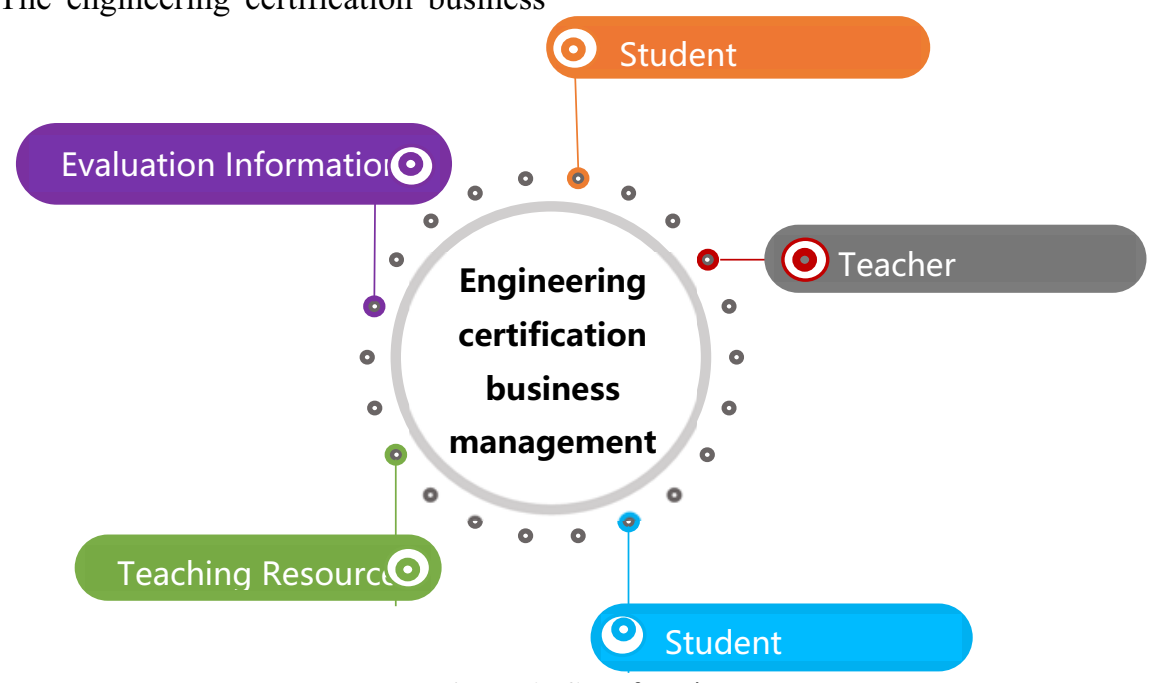

Figure 2. Core function

1. Student Information Management

This module consists of five parts: registration, information maintenance, information query, homework upload, and teaching evaluation. The data between each part is independent and has the function of connecting each data. Students can obtain relevant data through search engines.

2. Teacher Information Management

Teacher information management is an important function. Teachers need to evaluate and review whether students' overall information meets professional engineering certification. The module consists of five parts: application, information inquiry, information maintenance, student information management, and teaching plan management. In this module, teachers can inquire about the student's entrance score level, usual homework, classroom practice and test scores, etc. When there are changes in students, you can delete students, add new students, or complete student leave, various assessments and other tasks.

According to the needs of the project, the workload of teachers can be reduced by setting up project secondary administrators.

3. Student Assessment Management

This module is an innovative point different from other information management systems. It consists of six modules: question bank construction, exam registration and candidate management, intelligent $\mathrm{AI}$ exam, practice and electronic homework management, scholarship management, and student personal growth analysis. This system can query various information in the process of experimental teaching according to conditions such as courses, experimental content, teachers, etc., and automatically generate basic reports that conform to the Ministry of Education's management information standards and data submission format. It provides an open data import and export interface so that the system can realize data circulation with curriculum design, internship management, graduation thesis design and other systems. The system also has the functions of teacher evaluation and student evaluation, and provides evaluation templates and automatic summary, so that the quality of teaching can be managed.

4. Teaching Resource Management

This module has four parts: teacher information management, material information management, financial information management, and announcement feedback management. We designed this module based on the double standards of education and professional fields and combined with the needs of engineering positions. According to the information of surveyed students, teachers, schools, and so on, check whether the inspection 
object meets the basic requirements of civil engineering professional certification. In addition, in order to promote the smooth development of the project, a corresponding reward and punishment system has also been set up.

5. Evaluation Information Management

This module has three functions: evaluation material submission, evaluation material review, and evaluation information feedback. After the university collects the evaluation materials, they directly submit them to the evaluation information management system, and the evaluation committee $\operatorname{logs}$ into the system to review the evaluation materials and give feedback.

\section{System Architecture}

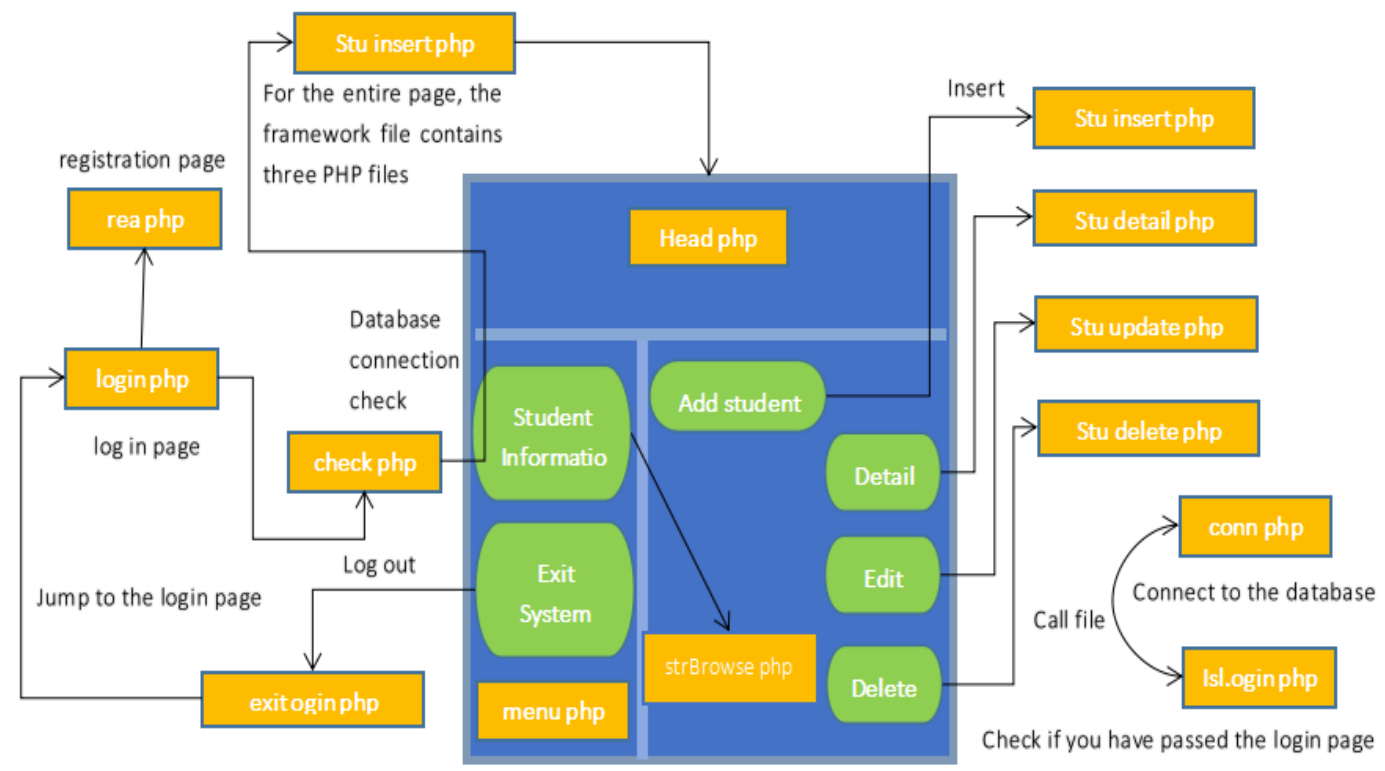

Figure 3. Subsystem organization structure

\subsection{Software Structure}

This system uses HTML/Css to make the system front desk, PHP language to write back-end business logic, and Mysql database to manage system data. It use modular

\subsection{Organization Structure}

The overall framework design of the system is divided into five major sections-student information management, teacher information management, student evaluation management, teaching resource management, and evaluation information management. Each section has a function corresponding to the characteristics of the module to realize the collection, collection and application of the process data and evaluation data of the training link, forming a continuous data chain required for professional certification.

Taking the "student information management" subsystem as an example, there are the detailed composition and process. It has been shown in chart 3 .

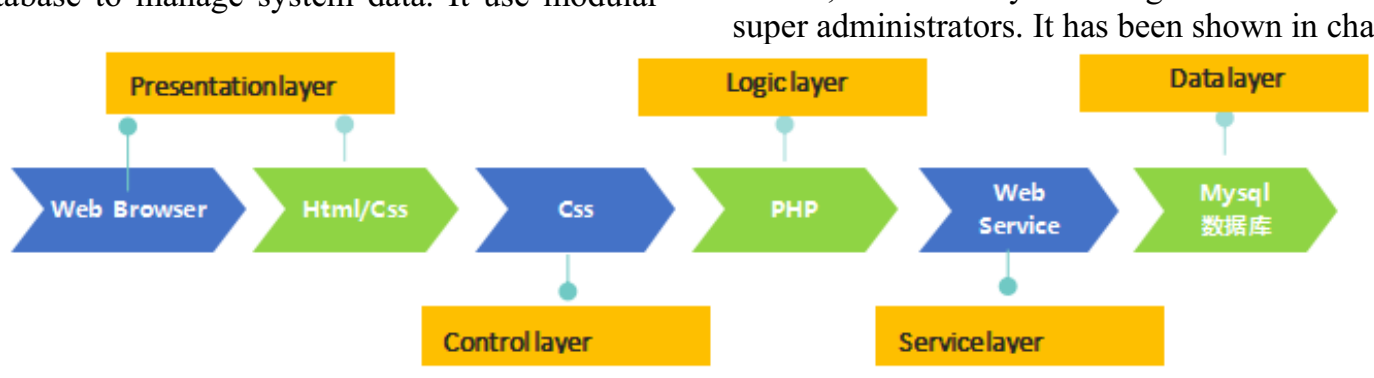

Figure 4. Software architecture diagram

\subsection{Hardware Structure}

Today is the "Internet +" era, with $5 \mathrm{G}, \mathrm{AI}$ and other hightech emerging. Cloud data centers and cloud service platforms are facing great challenges. Therefore, in order to provide a powerful and stable hardware backend, we adopt Alibaba Cloud servers, which have stable and design to decompose each functional module of the system, and implement corresponding functions according to requirements and needs, including the functions of student user registration, information entry, information review, information statistics, information review, and two-layer management of tutor users and super administrators. It has been shown in chart 4 . 


\section{System Implementation}

\subsection{System Interface}

The users of this system are divided into three categories: administrators, teachers, and students. The user needs to $\log$ in with an accurate account and password on the login interface, and the system calls 'check.php' to determine the validity of the user's information and whether the role is correct. Take the "student information management" subsystem as an example, when the account password is entered correctly and the system has passed the verification, the corresponding welcome interface will be entered. If you have not yet applied for an account, you can click the register button on this interface to enter the registration interface and fill in the relevant personal information to register. The background information administrator will review the identity of the new user and assign permissions. It has been shown in chart 5 .
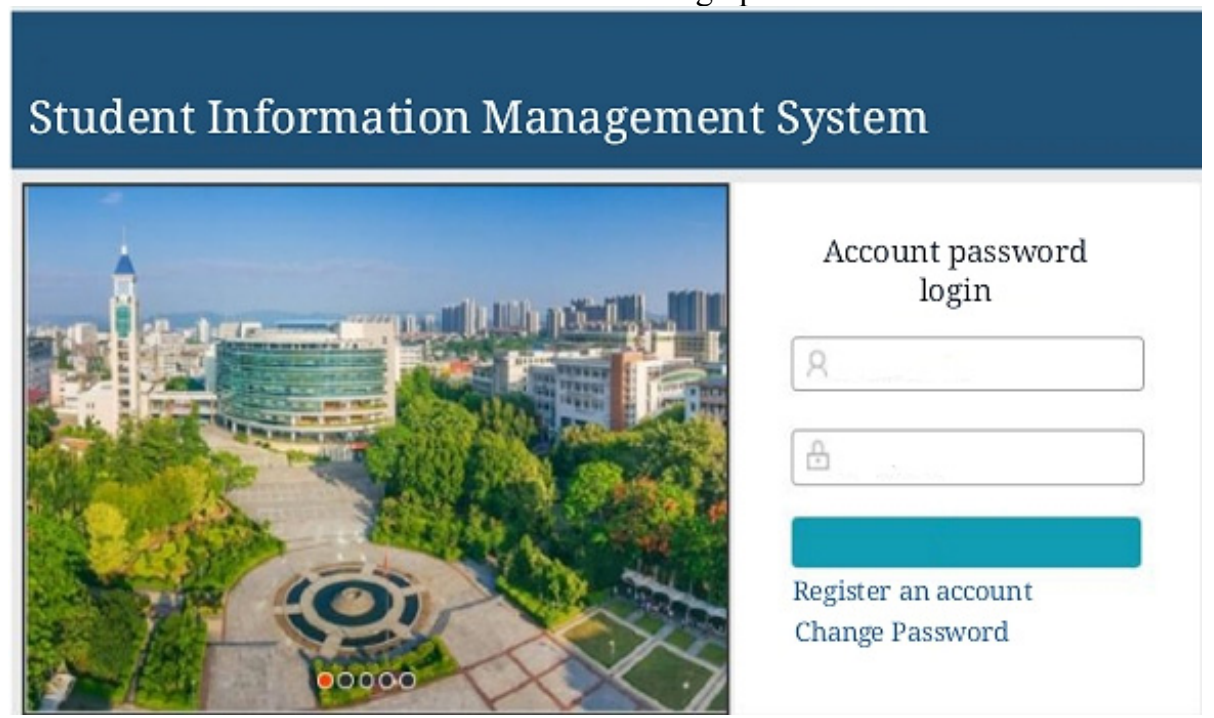

Account password

login

Figure 5. System Login Interface

The basic system information maintenance interface after logging in as an administrator. The administrator can manage, review and adjust basic information after logging in. The left side of the page is the module list, and the right side of the page is the content display. Inaddition, you can select through the search box on the upper right.At the same time, you can find the corresponding user information through the search box on the upper right. It has been shown in chart 6 .

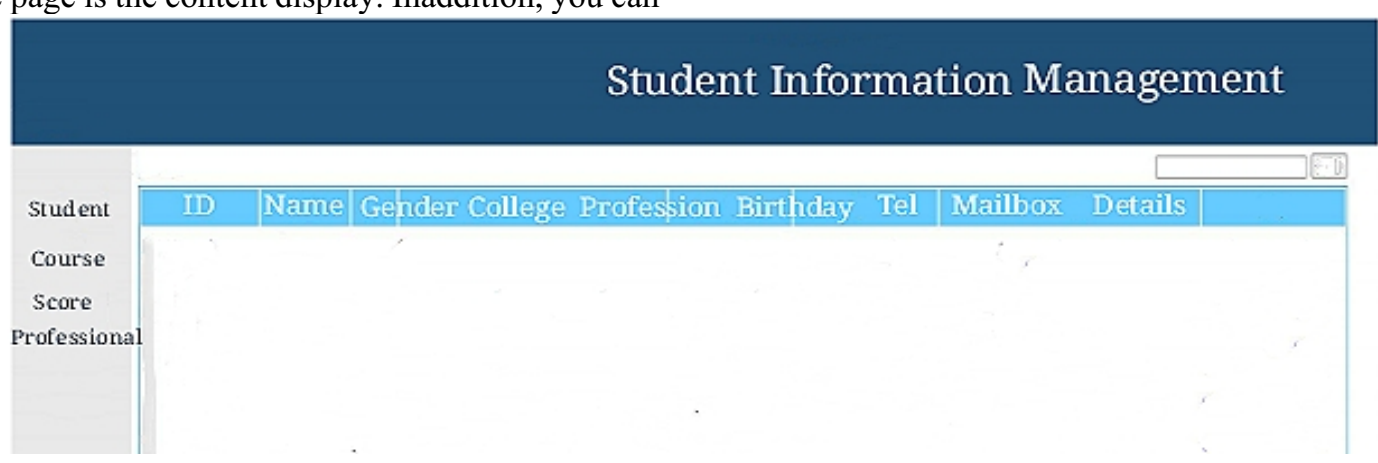

Figure 6. System main interface

\subsection{Related system interface}

We based on the PHP development environment, take the main.php as an example.

<!DOCTYPE html PUBLIC $\quad$ "-//W3C//DTD
"http://www.w3.org/TR/xhtml1/DTD/xhtml1-transitional.dtd">
<html xmlns="http://www.w3.org/1999/xhtml">
<head>
<meta http-equiv="Content-Type" content="text/html; charset=utf-8" />




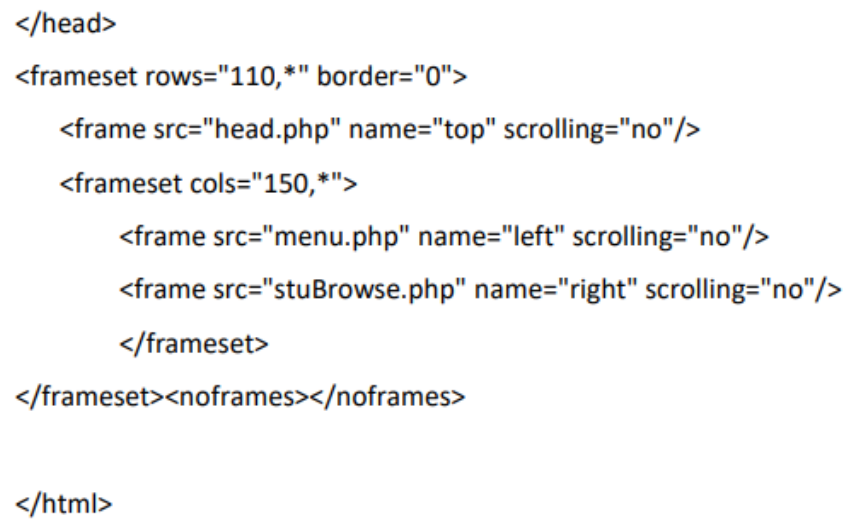

\section{Conclusions and Prospects}

Nowadays, the higher education certification system, as a unique mode and method of higher education quality assurance, has been widely adopted by western education developed countries. It has become an institutional element that responds to the social accountability of education and promotes and guarantees the development of education. ${ }^{[4]}$

Integrating the construction of subject evaluation with the current era of informatization data will surely form a major reform of professional certification and evaluation informatization in the future. Therefore, this system aims at the low efficiency of related data management in the process of civil engineering professional engineering education certification management. Based on the concept of engineering certification, the system uses information technology to integrate all the modules related to civil engineering certification.

\section{References}

1. Chaofeng Zhang, Jing Li, Jiandong Zhang, Honghong Chang. The enlightenment of joining the "Washington Agreement" on engineering undergraduate education[J]. High Education Journal, 2017(19): 8-11

2. Hai Zhang, Wei Fu. The construction of experimental teaching system for mechanical engineering majors for engineering education certification [J]. Experimental Technology and Management, 2017 (10): 166-169, 186.

3. China Engineering Education Professional Certification Association. Engineering Education Certification Self-evaluation Report Writing Guide (2016 Edition) [Z]. Beijing, 2015.

4. Jiancheng Wang. Research on American Higher Education Accreditation System [M]. Beijing: Education Science Press, 2007. 